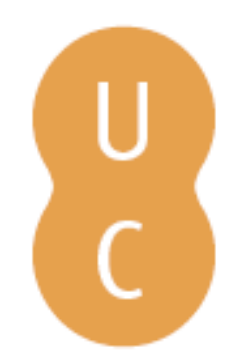

\title{
pommalina
}

\section{O ensino da escrita através do Programa de Desenvolvimento de Estratégias de Autorregulação (SRSD)}

\author{
Autor(es): $\quad$ Ferreira, Sara
}

Publicado por: Imprensa da Universidade de Coimbra

URL

persistente: URI:http://hdl.handle.net/10316.2/41804

DOI: $\quad$ DOI:https://doi.org/10.14195/978-989-26-1362-8_11

Accessed : $\quad$ 26-Apr-2023 16:30:53

A navegação consulta e descarregamento dos títulos inseridos nas Bibliotecas Digitais UC Digitalis, UC Pombalina e UC Impactum, pressupõem a aceitação plena e sem reservas dos Termos e Condições de Uso destas Bibliotecas Digitais, disponíveis em https://digitalis.uc.pt/pt-pt/termos.

Conforme exposto nos referidos Termos e Condições de Uso, o descarregamento de títulos de acesso restrito requer uma licença válida de autorização devendo o utilizador aceder ao(s) documento(s) a partir de um endereço de IP da instituição detentora da supramencionada licença.

Ao utilizador é apenas permitido o descarregamento para uso pessoal, pelo que o emprego do(s) título(s) descarregado(s) para outro fim, designadamente comercial, carece de autorização do respetivo autor ou editor da obra.

Na medida em que todas as obras da UC Digitalis se encontram protegidas pelo Código do Direito de Autor e Direitos Conexos e demais legislação aplicável, toda a cópia, parcial ou total, deste documento, nos casos em que é legalmente admitida, deverá conter ou fazer-se acompanhar por este aviso.

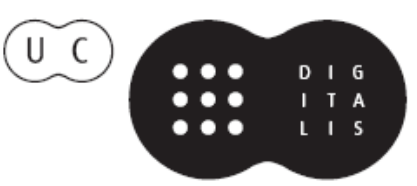




\section{PESSOAS E IDEIAS EM TRÂNSITO}

Percursos e Imaginários

RITA BASÍLIO DE SIMÕES

CLARA SERRANO

SÉRGIO NETO

JOÃO MIRANDA

(ORGS.)

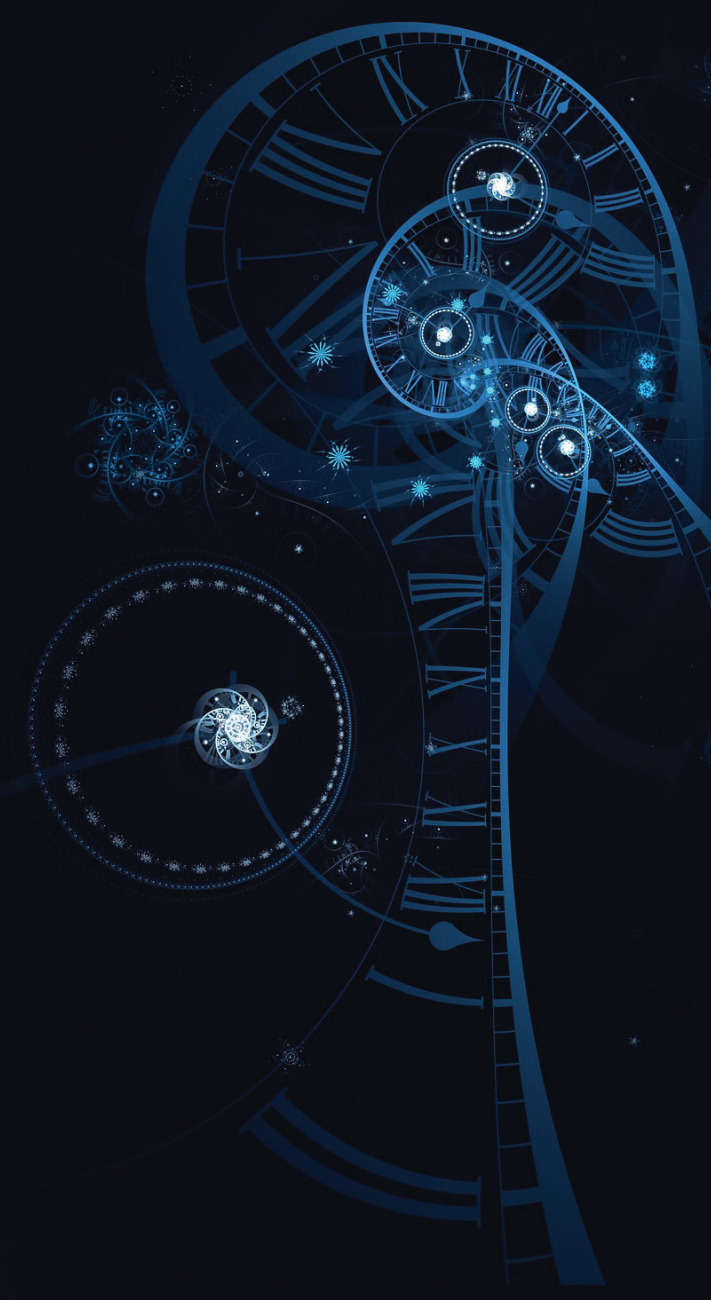

IMPRENSA DA

UNIVERSIDADE

DE COIMBRA

COIMBRA

UNIVERSITY

PRESS 


\section{O ENSINO DA ESCRITA ATRAVÉS DO PROGRAMA DE DESENVOLVIMENTO DE ESTRATÉgIAS DEAUTORREGULAÇÃO (SRSD)}

Sara Ferreira FPCEUC

Resumo: O projeto de doutoramento intitulado O ensino da escrita através do Programa de Estratégias de Autorregulação (SRSD), que aqui se apresenta, tem como objetivos gerais adaptar algumas estratégias deste programa, nomeadamente as que se referem à planificação do ensaio de opinião e do texto expositivo, e verificar os efeitos da sua instrução na escrita de alunos do $8 .^{\circ}$ ano.

Palavras-chave: Autorregulação da aprendizagem; Composição de textos; Escrita; Estratégias de escrita; Formação de professores.

Abstract: The doctoral project Teaching to write through the Self-Regulated Strategy Development (SRSD) was approved and financed by the Foundation for Science and Technology (FCT). Its general goals are to adapt some strategies of this program, specifically those relating to the planning of the opinion essay, and expository text, in order to verify the effects of the instructions in the writing of $8^{\text {th }}$ grade students. Key-words: Self-regulated learning; Teacher training; Text composition; Writing; Writing strategies. 


\section{Introdução}

Atualmente, o domínio da escrita é um requisito básico para a participação na vida em sociedade, sendo que ensinar a escrever é uma tarefa do sistema educativo. Contudo, muitos são os alunos que manifestam dificuldades nesta área, quer num nível elementar quer num nível mais avançado.

Face aos problemas na escrita evidenciados pelos alunos portugueses, em estudos nacionais e internacionais (GAVE, 2011; GIASE, 2004/2005; Sousa, 2011) pretendemos, com o projeto $O$ ensino da escrita através do Programa de Estratégias de Autorregulação (SRSD) (SFRH/BD/84392/2012), contribuir para o progresso e reforço das técnicas de ensino da composição escrita e, consequentemente, para o sucesso académico dos alunos.

Seguindo o Programa de Desenvolvimento de Estratégias de Autorregulação (Self-Regulated Strategy Development - SRSD) (Harris et al., 2008), desenvolvemos, nas turmas do $8 .^{\circ}$ ano de escolaridade de duas escolas do concelho de Coimbra, um programa de ensino de estratégias de planificação do texto expositivo e outro do ensaio de opinião.

Com este estudo pretendemos, através da aplicação do SRSD, averiguar a eficácia do ensino de estratégias de escrita nas tipologias textuais já referidas e verificar se a aprendizagem de uma determinada tipologia é transferível para outra.

\section{O ensino da escrita de textos}

A aprendizagem da escrita é uma exigência elementar que capacita os alunos para a composição de textos (Rebelo, 2008).

No entanto, a escrita, entendida como a composição de textos a serem lidos por pessoas que não estão presentes, é uma 
competência complexa que necessita de esforço e tempo para ser dominada (Bereiter \& Scardamalia, 1987; Festas, 2002; Graham \& Perin, 2007; Kellogg, 1994). Especificamente, requer conhecimentos de natureza mecânica (e.g. caligrafia), convencional (e.g. ortografia, pontuação), linguística (e.g. sintaxe) e cognitiva (e.g. conteúdo, estrutura, organização interna dos textos) (Alamargot \& Fayol, 2009).

Ao nível das aprendizagens escolares, o ensino da escrita é obrigatório, estendendo-se a todos os níveis de escolaridade e à maior parte das áreas curriculares. Apesar disto, o mesmo tem sido negligenciado, o que se vem refletindo no desempenho dos alunos. Por outro lado, os programas de Português têm-se centrado maioritariamente nas componentes convencional, linguística e mecânica em detrimento da componente cognitiva (Duarte, 2008).

O Ministério da Educação e Ciência identifica a existência de dificuldades dos alunos portugueses relativamente às competências da escrita (GAVE, 2011; Sousa, 2011). No Relatório dos Exames Nacionais de 2011 sugere-se o reforço de estratégias com base em modelos processuais de escrita, reiterando-se "a importância de intervenções didáticas que privilegiem um ensino da escrita assente, igualmente, na explicitação de características de tipologias, tendo em vista um domínio multifuncional desta competência, transversal e crucial para o sucesso na vida académica" (Sousa, 2011, p. 13). Relativamente ao ensino da escrita em Portugal, Duarte afirma ainda que "Os alunos devem ser capazes de escrever textos bem articulados de diferentes tipologias [...] Ora para serem textualmente competentes, os jovens têm de ter sido objeto de aprendizagens e treinos vários no que concerne várias questões de Linguística Textual..." (Duarte, 2008, pp. 9-10).

Embora não exista unanimidade quanto à classificação da tipologia textual, considera-se que o conhecimento do seu conceito 
pelos alunos seja fundamental, quer para a compreensão, quer para a produção de textos (Adam, 1992; Duarte, 2008; Preto-Bay, 2005).

Nas últimas décadas, a investigação na área da escrita tem tido alguns progressos significativos, o que se ficou a dever à tomada de consciência de investigadores e educadores das dificuldades referidas anteriormente e comprovadas por vários estudos. Daí surgiram várias teorias e modelos vocacionados para o seu ensino, tal como o Programa de Desenvolvimento de Estratégias de Autorregulação (Harris et al., 2008) que integra várias linhas de investigação e é um dos modelos mais estudados e aplicados no ensino da escrita. Também em Portugal esta área tem sido objeto de preocupação, o que se tem refletido num aumento do número de estudos, entre os quais se incluem o Projeto "Ensino de Estratégias de Escrita" (PTDC/CPE-CED/102010/2008), que adaptou para a língua e contexto educacional português as estratégias relativas ao ensaio de opinião do SRSD, tendo-se verificado uma melhoria significativa das competências de escrita dos alunos nesta tipologia específica (Ferreira et al., 2012; Rebelo et al., 2012; Sousa et al., 2012).

\section{O Programa de Desenvolvimento de Estratégias de Autorregulação (Self-Regulated Strategy Development - SRSD)}

O Programa de Desenvolvimento de Estratégias de Autorregulação é um modelo de instrução de estratégias de escrita que tem vindo a ser desenvolvido desde 1982, e cuja eficácia tem sido amplamente comprovada ao longo de três décadas de investigação (Graham, 2008; Graham \& Perin, 2007; Harris et al., 2008).

Tendo, inicialmente, sido concebido para ajudar alunos com dificuldades de aprendizagem, os investigadores verificaram que também os alunos que não manifestavam essas dificuldades 
apresentavam problemas semelhantes ao nível da escrita (e. g. erros ortográficos, textos demasiado curtos e pouco elaborados, revisão pouco eficaz, etc.). Deste modo, o SRSD tem sido aplicado com sucesso em contexto de sala de aula, com pequenos grupos, individualmente e em situação de tutoria, desde o primeiro ciclo até ao ensino superior (Harris et al., 2011; Harris et al., 2012). Mas a área de intervenção deste programa não se tem reduzido ao ensino de estratégias de escrita, tendo também sido utilizado para ajudar os alunos a soletrar, a ler e na matemática (Harris et al., 2008).

Assim sendo, e focando-nos na área da escrita, os três grandes objetivos deste programa são: auxiliar os alunos a dominar os processos cognitivos envolvidos na planificação, produção, revisão e edição da escrita; ajudar os alunos a desenvolver a capacidade de monitorizar e gerir a sua escrita; contribuir para o desenvolvimento de atitudes positivas dos alunos perante a escrita e sobre si próprios enquanto escritores.

O SRSD tem seis estádios de instrução utilizados para desenvolver e integrar o uso de estratégias de escrita e elementos de autorregulação: Desenvolver e ativar os conbecimentos prévios; Discutir; Modelar; Memorizar; Apoiar; e Desempenho autónomo (Harris et al., 2008; Harris et al., 2011).

Estes são apresentados pelos autores como linhas orientadoras, e não como etapas fixas e predeterminadas, uma vez que podem ser reordenados, modificados, repetidos ou eliminados, de acordo com as necessidades e ambições dos professores e dos alunos, que devem trabalhar de forma colaborativa neste processo.

No primeiro estádio - Desenvolver e ativar os conbecimentos prévios - os alunos devem adquirir determinados pré-requisitos (e.g. conhecimentos, vocabulário e conceitos relativos à tipologia textual) para que as estratégias de escrita e de autorregulação possam ser aprendidas e aplicadas com sucesso. 
Já no segundo estádio - Discutir - o professor e os alunos discutem o significado da aprendizagem e do uso das estratégias de escrita e de autorregulação.

No terceiro estádio - Modelar - o professor modela a aplicação das estratégias de escrita e autorregulação (e.g. autoafirmações) que se pretende que o aluno aprenda.

Segue-se o quarto estádio - Memorizar - onde os alunos devem memorizar os passos das estratégias de composição de textos (através de mnemónicas).

No quinto estádio - Apoiar - os alunos usam as estratégias aprendidas de forma colaborativa e, se necessário, com o auxílio do professor, o qual vai decrescendo ao longo deste processo.

Finalmente no último estádio - Desempenho autónomo - os alunos devem já utilizar autonomamente as estratégias de escrita e de autorregulação, sendo monitorizados pelo professor.

\section{O presente estudo}

É perante a necessidade de um ensino explícito de estratégias de escrita realmente eficazes para diferentes tipologias textuais (Duarte, 2008; Harris et al., 2008; Preto-Bay, 2005) que surge o nosso projeto de investigação.

Desta forma, e tendo em conta os objetivos traçados, realizámos um estudo quase-experimental, com pré e pós-testes. Começámos por fazer os pedidos de autorização necessários à Direção Geral de Educação, ao Agrupamento de escola e aos encarregados de educação. A nossa amostra é constituída por 185 alunos que frequentaram, no ano letivo de 2013-2014, o $8 .^{\circ}$ ano de escolaridade em duas escolas básicas do concelho de Coimbra escolhidas criteriosamente com vista à equivalência dos dois grupos a formar. 
Baseando-nos no SRSD, adaptámos o conjunto de lições do texto expositivo para a língua e contexto portugueses e, por outro lado, recorremos às estratégias de ensino de escrita do ensaio de opinião, desenvolvido e testado no âmbito do Projeto "Ensino de Estratégias de Escrita" (PTDC/CPE-CED/102010/2008), as quais sofreram algumas reformulações tendo em conta a análise de algumas dificuldades surgidas e sugestões recolhidas nesse mesmo projeto.

Para além dos materiais já referidos, construímos ainda alguns instrumentos de avaliação necessários ao presente estudo (e.g. provas de avaliação, questionários, ficha sociodemográfica, etc.).

Deste modo, a cada escola foi atribuída uma das duas condições: numa foram ensinadas as estratégias de escrita do texto expositivo; e na outra foram ensinadas as estratégias do ensaio de opinião, assim como estratégias de autorregulação em ambas as escolas. Assim, a fase de intervenção consistiu na aplicação de dois projetos de escrita, que foram integrados e decorreram, semanalmente, nas aulas de Português. Cada sessão teve a duração de 45 minutos e esteve a cargo das professoras de Português das turmas participantes neste projeto. Contudo, em algumas sessões, estiveram presentes dois elementos da equipa de investigação que coadjuvaram as professoras no apoio aos alunos.

Este estudo compreendeu ainda uma componente de formação de professores, creditada pelo Conselho Científico-Pedagógico da Formação Contínua, que decorreu ao longo de todo o ano letivo. Esta teve a duração de 50 horas, na modalidade de "oficina de formação", sendo as destinatárias as professoras que participaram nos projetos de escrita. De forma a prepará-las para a tarefa de aplicação dos mesmos, foram realizadas sessões conjuntas, com todas as professoras, onde foram abordados os princípios pedagógicos do SRSD. Já nas sessões de formação específicas de cada escola, foram trabalhados de forma exaustiva os guiões de cada lição e técnicas de ensino de estratégias de autorregulação. 


\section{Considerações finais}

Os resultados alcançados em inúmeras meta-análises vieram comprovar que, efetivamente, o ensino de estratégias de escrita, nomeadamente com recurso ao modelo SRSD, é eficaz na melhoria da qualidade de escrita, independentemente das características dos alunos, do ano de escolaridade que frequentam ou da tipologia textual trabalhada.

Também em Portugal, a eficácia deste modelo específico foi comprovada em duas investigações (Ferreira et al., 2012; Limpo \& Alves, 2013; Rebelo et al., 2012; Sousa et al., 2012), o que nos motivou a estender a pesquisa ao texto expositivo.

Sendo o domínio da escrita uma competência transversal a todo o currículo, pretendemos verificar a eficácia do ensino de estratégias de escrita e de autorregulação na composição de textos e no desempenho escolar dos alunos em geral.

Finda a fase de classificação e análise dos textos produzidos pelos alunos, que está ainda a decorrer, esperamos, por um lado, que estes apresentem melhores resultados na tipologia textual trabalhada no seu grupo e que os alunos que trabalharam o texto expositivo revelem um maior progresso, ao nível da escrita, em outras disciplinas relativamente ao grupo de controlo.

\section{Referências Bibliográficas}

Adam, J. M. (1992). Les textes: Types et Prototypes - Récit, description, argumentation, explication et dialogue. Paris: Nathan.

Alamargot, D.; Fayol, M. (2009). Modelling the Development of Written Composition. In Beard, R., et al (Eds). The SAGE Handbook of Writing Development. London: SAGE.

Bereiter, C.; Scardamalia, M. (1987). The psychology of written composition. London: Lawrence Erlbaum Associates.

Duarte, I. M. (2008). Ensino da língua portuguesa em Portugal: o texto, no cruzamento dos estudos linguísticos e literários (210-232). In Língua Portuguesa: educação \& mudança. Rio de Janeiro: Editora Europa. 
Ferreira, S.; Prata, M.; Inácio, M.; Sousa, C.; Festas, M. I.; Oliveira, A. L. (2012). Ensino de estratégias de escrita em aulas de Língua Portuguesa. In Atas da I Conferência Internacional Investigação, Práticas e Contextos em Educação (109-113). Leiria: ESECS - Instituto Politécnico de Leiria.

Festas, M. I. (2002). Principais tendências no ensino da escrita de textos. Psychologica, 30, 173-185.

GAVE (2011). Provas de Aferição $2{ }^{\circ}$ ciclo - Língua Portuguesa. Lisboa: Ministério da Educação.

GIASE (2004/2005). Estatísticas da Educação 04/05. Lisboa: Ministério da Educação.

Graham, S.; Perin, D. (2007). Writing next: Effective strategies to improve writing of adolescents. In middle and high school $-A$ report to Carnegie Corporation of New York. Washington: Alliance for Excellent Education.

Graham, S. (2008). Effective Writing Instruction for all students. Wisconsin: Renaissance Learning.

Harris, K. R.; Graham, S.; Manson, L.; Friedlander, B. (2008). Powerful Writing Strategies for all Students. Baltimore: Paul H. Brookes Publishing Co.

Harris, K.; Graham, S.; MacArthur, C.; Reid, R.; Mason, L. (2011). Self-Regulated Learning Process and Children's Writing. In Zimmerman, B. \& Schunk, D. (Ed). Handbook of Self-Regulation of learning and performance. New York: Routledge.

Harris, K.; Lane, K.; Graham, S.; Driscoll, S.; Sandmel, K.; Brindle, M.; Schatschneider (2012). Practice-Based Professional Development for Self-Regulated Strategies Development in Writing: a randomized controlled study. Journal of Teacher Education, 63 (2), 103-119.

Kellogg, R. T. (1994). The psychology of writing. New York: Oxford University Press.

Preto-Bay, A. M. R. (2005). Alguns aspectos pedagógicos do ensino da escrita: o processo e o género textual. Revista Portuguesa de Pedagogia, 39 (1), 7-27.

Limpo, Teresa; Alves, Rui (2013). Teaching planning or sentence-combining strategies: Effective SRSD interventions at different levels of written composition. Contemporary Educational Psychology, 38, 328-341.

Rebelo, J. A. S. (2008). Dificuldades na aprendizagem da escrita. Dificultades de aprendizaje en la escritura. In Arroyo, R. G.. La Comunicácion escrita: Cognición, multilinguismo y tecnologias (113-139). Granada: Editorial Natívola.

Rebelo, J.; Ferreira, S.; Festas, M. I.; Inácio, M.; Prata, M.; Sousa, C.; Oliveira, A. L. (2012). Teaching Writing Strategies in Portuguese Language Classes Using the Self-Regulated Strategy Development (SRSD) Model. Paper presented at the International Couseling and Education Conference (ICEC). Istambul: Turkey.

Sousa, Hélder Dinis (Coord.), (2012). Exames nacionais - Relatório 2011. Lisboa: GAVE.

Sousa, C.; Inácio, M.; Ferreira, S.; Prata, M.; Festas, M.; Oliveira, A. (2012). O modelo Self-Regulated Strategy Development no ensino da escrita do ensaio de opinião. In L. Mata, F. Peixoto, J. Morgado,V. Monteiro, \& J. Silva (Eds.). Atas do 12. ${ }^{\circ}$ Colóquio Internacional de Psicologia e Educação, 1284-1295. 